\title{
A "Wear and Tear" Hypothesis to Explain Sudden Infant Death Syndrome
}

\section{Eran Elhaik* \\ Department of Animal and Plant Sciences, University of Sheffield, Sheffield, UK}

Sudden infant death syndrome (SIDS) is the leading cause of death among USA infants under 1 year of age accounting for $~ 2,700$ deaths per year. Although formally SIDS dates back at least 2,000 years and was even mentioned in the Hebrew Bible (Kings 3:19), its etiology remains unexplained prompting the CDC to initiate a sudden unexpected infant death case registry in 2010. Due to their total dependence, the ability of the infant to allostatically regulate stressors and stress responses shaped by genetic and environmental factors is severely constrained. We propose that SIDS is the result of cumulative painful, stressful, or traumatic exposures that begin in utero and tax neonatal regulatory systems incompatible with allostasis. We also identify several putative biochemical mechanisms involved in SIDS. We argue that the important characteristics of SIDS, namely male predominance (60:40), the significantly different SIDS rate among USA Hispanics (80\% lower) compared to whites, $50 \%$ of cases occurring between 7.6 and 17.6 weeks after birth with only $10 \%$ after 24.7 weeks, and seasonal variation with most cases occurring during winter, are all associated with common environmental stressors, such as neonatal circumcision and seasonal illnesses. We predict that neonatal circumcision is associated with hypersensitivity to pain and decreased heart rate variability, which increase the risk for SIDS. We also predict that neonatal male circumcision will account for the SIDS gender bias and that groups that practice high male circumcision rates, such as USA whites, will have higher SIDS rates compared to groups with lower circumcision rates. SIDS rates will also be higher in USA states where Medicaid covers circumcision and lower among people that do not practice neonatal circumcision and/or cannot afford to pay for circumcision. We last predict that winter-born premature infants who are circumcised will be at higher risk of SIDS compared to infants who experienced fewer nociceptive exposures. All these predictions are testable experimentally using animal models or cohort studies in humans. Our hypothesis provides new insights into novel risk factors for SIDS that can reduce its risk by modifying current infant care practices to reduce nociceptive exposures.

Keywords: sudden infant death syndrome, allostatic load, neonatal circumcision, trauma, pain, stress

\section{BACKGROUND}

\section{The Etiology of Sudden Infant Death Syndrome}

Sudden infant death syndrome (SIDS) (9ICD 798.0; 10ICD R95), "crib death," or "cot death" was first coined in 1953 and by 2004 was defined as: "the sudden unexpected death of an infant under 1 year of age, with onset of the fatal episode apparently occurring during sleep, that remains unexplained 
after a thorough investigation, including performance of a complete autopsy and review of the circumstances of death and the clinical history" (1). SIDS classification spurred the development of diverse approaches to determine the cause of death in order to exclude deaths due to accidental or non-accidental injuries, suffocation and strangulation, or medical causes $(2,3)$. Despite the publication of $\sim 11,000$ SIDS-related articles (4), of which over 100 SIDS studies appearing in Medical Hypotheses, biomarkers are still unavailable (5) and SIDS remains the leading cause of death for infants between 1 month and 1 year in western countries (accounting for 2,700 deaths per year in 2010 in USA) (6). In developed countries, the 2005 SIDS rates (birth to 1 year) ranged from 0.16 (Japan) to 0.54 (United States) per 1000 live births (7). Using non-Hispanic whites as a reference point (1), SIDS rates are 1.41 per 1000 live births in non-Hispanic blacks and 0.46 in Hispanics (8). In the absence of a proven intervention even if prospective identification was feasible, SIDS is one of the most frequent worries for parents.

Although prone sleeping campaigns, such as "Back to Sleep" reduced SIDS and postneonatal mortality rates in the 1990s (9), their effect was uneven in different countries (10). Subsequent to 1999, the plateau, or slower decline in SIDS rates, has been associated with a diagnostic shift from classification of SIDS deaths $(11,12)$ to a concurrent increase in rates of other categories of sleep associated sudden and unexpected infant deaths attributed to accidental suffocation and strangulation in bed or "unknown" causes (13), questioning the magnitude of the actual decrease in SIDS deaths $(14,15)$. While no confirmed SIDS biomarkers exist [e.g., Ref. $(16,17)]$ nor it is possible to differentiate accidental asphyxia from SIDS (18), a number of modifiable risk factors have been associated with SIDS, including prone sleep position, parental smoking during and after pregnancy, alcohol consumption by caregivers, overheating, preterm infants, infant head covering by soft bedding, bed sharing, and upper respiratory tract infection (19-21). Decreasing in these risk factors was effective in reducing the mortality rates over the past two decades (22), though not necessarily SIDS, which remains distinct from known mortalities and its main characteristics - male predominance (60:40 male:female USA ratio), significantly lower SIDS rates in USA Hispanics compared with whites, infants aged 2-4 months being at greatest risk of SIDS with most SIDS-related deaths occurring by 6 months, and seasonal variation with most cases occurring during winter $(8,23)$ - remain largely unexplained. Here, we propose an allostasis-based model to explain SIDS and argue that it explains SIDS's main characteristics (Table 1).

\section{The Allostasis Model}

The allostasis model assigns a central role to the brain as the organ of stress and adaptation in enabling efficient regulation of the internal milieu (24). Facing low- or high-level toxic and pathologic stressors, the brain attempts to adapt via neuroendocrine and autonomic signals and through the synaptic plasticity facilitated by multiple epigenetic mechanisms during early development (25-27). The cumulative effect of stressors on the brain and body for either potentially protective or pathologic responses is termed allostatic load or overload, respectively (27). An allostatic overload occurs when allostatic responses that allow neurophysiologic stress systems to function at critical periods of the developing nervous system are maladaptive for future environmental stressors. The physiological cost of increased allostatic load has also been dubbed a "wear and tear" process (28) and encompasses both the prenatal and postnatal periods (29).

We postulate that while low-level stress can stimulate adaptation, prolonged and repetitive iatrogenic stressful, painful, or traumatic experiences during prenatal, perinatal, neonatal, and postneonatal development constitute allostatic overload and are risk factors for SIDS. Due to their total dependence, the infant's ability to allostatically regulate exposure to stressors is severely constrained (30), which increases their vulnerability to disease and premature death (26) (Figures 1 and 2). Due to their difficulties in maintaining homeostasis and inability to escape/ avoid iatrogenic or non-medically nociceptive exposure, infants are vulnerable to toxic stress with preterm infants being the most vulnerable (31).

\section{Stress Experienced in utero}

Infants begin to experience various stresses in utero due to maternal smoking or drug abuse (19), caffeine consumption (32), maternal inflammation, and traumatic injuries that account toward allostatic load. Interestingly, several authors have shown sex-dependent changes in pain responsiveness at maturity in animals having experienced repeated neonatal pain in utero and infancy. For example, Mueller and Bale (33) showed that stress experienced early in pregnancy created maladaptive behavioral stress responsivity, anhedonia, and an increased sensitivity to selective serotonin reuptake inhibitor treatment. Provided the lower expression of DNMT1, the enzyme responsible for methylation maintenance in male placentas compared to females, the authors reasoned that females are able to circumvent the effects of stress by strengthening the maintenance of methylation during

TABLE 1 | The main characteristic of SIDS explained by the allostatic load hypothesis.

SIDS characteristic

Male predominance $(60: 40)$

SIDS rate in the USA vary between Hispanics and whites

Mortality peaks between 2 and 4 months

Seasonal variation with most cases occurring during winter

\section{Allostatic load hypothesis}

Females are more resilient to nociceptive stimuli than males, which reduces their allostasis compared to males. Male circumcision further increases male allostasis.

Circumcision rates among Hispanics are much lower than in non-Hispanic white.

Infants lose the protection of maternally acquired antibodies at 2-4 months of age. The wound healing procedure from circumcision may increase susceptibility to infection peaks during the same period. Preterm infants have also decreased heart rate variability at that period (corrected age).

Waning of maternal antibody levels and/or low levels of acquired immunity followed by recent infection and inflammation during a developmental period in the infant increase the allostatic load. 


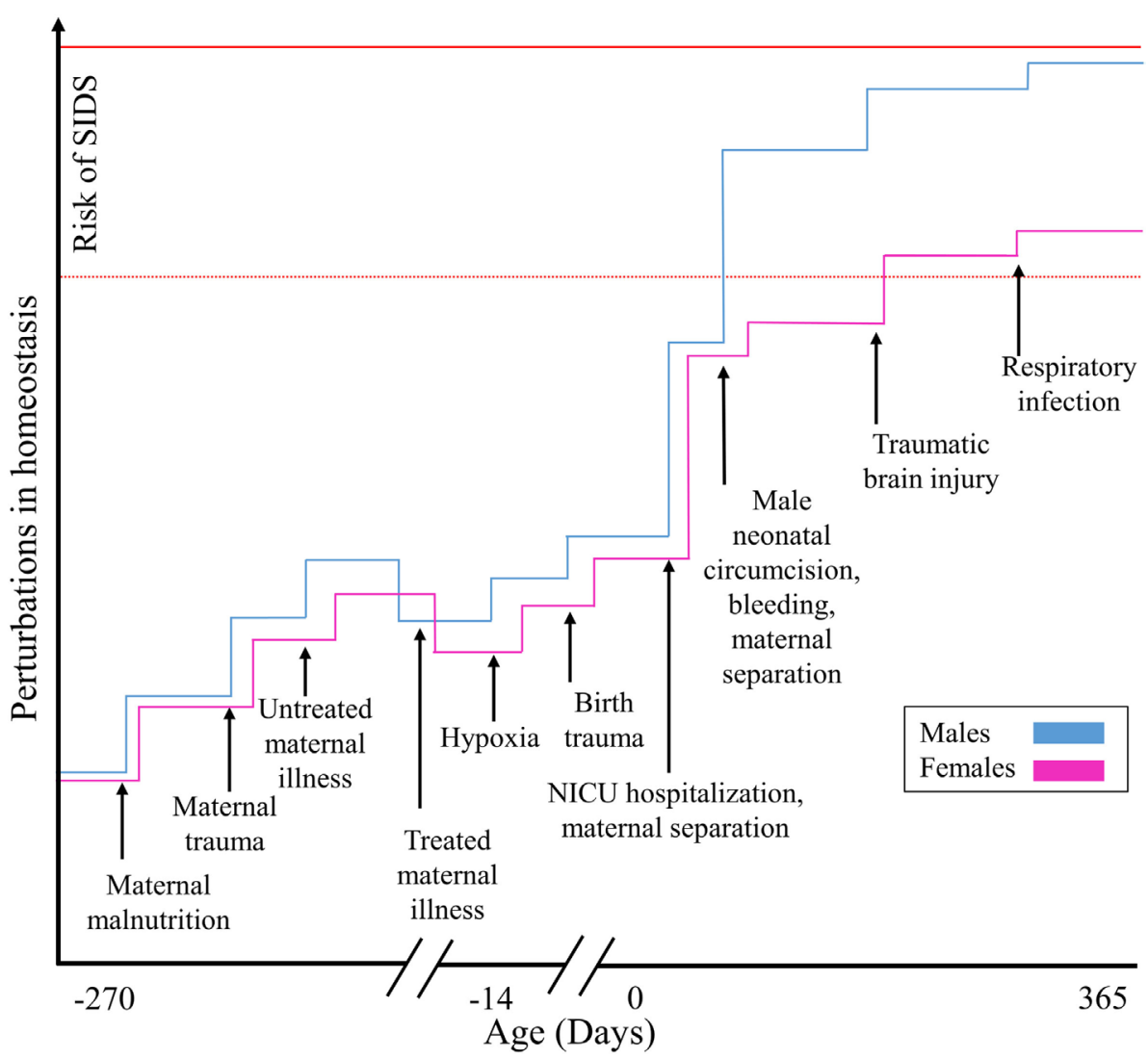

FIGURE 1 | Illustrating how SIDS is explained by the allostatic load model for males and females. Cumulative stressful, painful, or traumatic stimuli contribute additively toward an increased risk of SIDS.

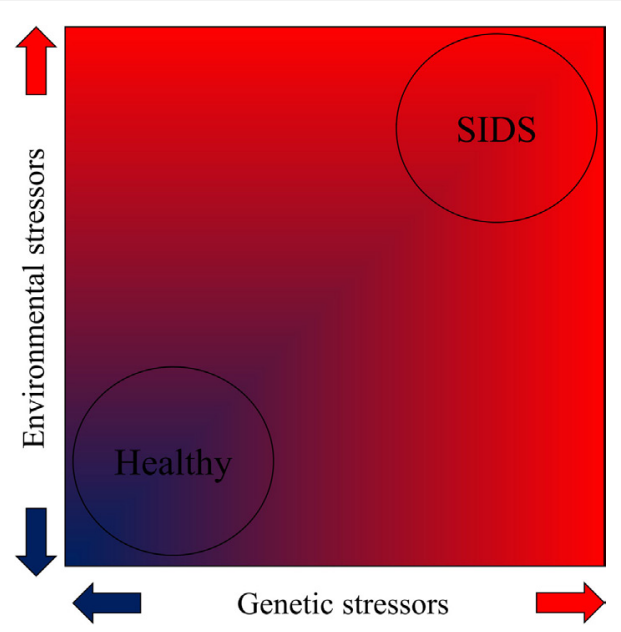

FIGURE 2 | The contribution of genetic and environmental stressors toward SIDS according to the allostatic load model as demonstrated by a heat map (red indicates high stress).

perturbations. Page et al. (34) reported a higher mechanical sensitivity in male rats in response to neonatal-paw-needle-stick, whereas females showed increased sensitivity to inflammatory stimuli. Such female "protective effects" may be attributed to hypothalamic-pituitary-adrenal (HPA) axis hormones known to be elevated in females both at baseline and in response to stress (35). Indeed, Paterson et al. (36) reported that SIDS cases had a significantly larger deficiency in serotonin $5-\mathrm{HT}_{1 \mathrm{~A}}$ receptors compared with controls $[\mu=53.9(\sigma=19.8)]$ and that male SIDS cases had significantly lower receptor counts [16.2 (4.8)] compared with female SIDS cases [29.6 (16.5)].

\section{Preterm Births}

It is known that the postnatal age for SIDS and other deaths of unknown causes decreases as gestational age (GA) at birth progresses. What remains unknown is why preterm infants remain at increased risk for sudden infant death despite the dramatic drop in rates since the 1990s and whether the increased risk across all categories of sudden infant death suggest a common mechanism (37). We speculate that preterm infants are at an increased risk due to their immature organ systems and the multiple stressors they experience during hospitalization and later on.

Preterm infants (24-32 weeks), physiologically unprepared for the stress outside the protective intrauterine environment, are hospitalized for lengthy periods where they are exposed to multiple stressors, including extended exposure to light, noise, acute and chronic illness, maternal separation, invasive procedures, 
handling, multiple medications, endotracheal intubation, repeated blood tests, insertion of peripheral lines, and surgery $(38,39)$. Preterm infants who experienced at least 40 days of intensive care have increased brain neuronal responses to noxious stimuli compared to healthy newborns at the same age (40). The cumulative effect of these early repetitive pain/adverse experiences on perinatal brain plasticity contributes to the observed neurodevelopmental and behavioral abnormalities associated with early life stress and allostasis (40-42).

Preterm infants are also at higher risk of hypoxia than term infants. Following hypoxia, infants maintain adequate tissue oxygenation through perfusion by prompting an increase in heart rate to maintain cardiac output. The heart is relatively insensitive to hypoxia in infancy, as opposed to hypercapnia, which rises rapidly during asphyxia and leads to adrenal and catecholamine release that increases heart rate and blood pressure (43). Infants who succumb to life-threatening cyanosis/asphyxia have been observed to breathe vigorously/gasp but without an increase in heart rate, suggesting an abnormal/impaired tachycardia response to hypercapnia despite ventilatory efforts (43). An impaired baroreflex sensitivity can result in a failure to control perfusion pressure. Very preterm infants have impaired and delayed maturation of baroreflex sensitivity (44) and decreased heart rate variability at peak SIDS age of 2-3 months (corrected age) consistent with delayed maturation of parasympathetic innervation regardless of sleeping position (45). Cerebral autoregulation is also impaired in preterm infants with decreased cerebral oxygenation in the prone position and increased variability in cerebral oxygenation with head up tilt (orthostatic challenge) indicating greater risk of cerebral hypoxia and immature cerebrovascular control in preterm infants over the first 6 months (46).

\section{Non-Urgent Pediatric Surgeries}

Concerns that pediatric surgeries requiring general anesthesia are toxic stressors that elicit long-term deficits in cognitive and learning behavior have been the subject of recent reviews [e.g., Ref. (47, 48)]. The 2014 Food and Drug Administration (FDA) Science Board reviewing anesthetic neurotoxicity stated that the data "are sufficient to conclude that adverse effects noted in juvenile animals are reasonably expected to occur in developing humans" (49). The FDA Board recommended avoiding non-urgent surgical procedures in children younger than 3 years of age (48). In addition to general anesthesia, the risk of local anesthetic neurotoxicity, due to lack of adequate studies of safety and effectiveness in the developing infant, has recently been highlighted (50).

The surgery itself may elicit neural injury in neonates (51). The significantly increased risk of death or neurodevelopmental impairment in very low birth weight newborns following major or minor surgery that does not require a general anesthetic (52) is consistent with nociceptive exposure, pain, and overall neurotoxic risk $(47,53,54)$. The American Academy of Pediatrics (AAP) and the Canadian Pediatric Society (CPS) have recognized the neurotoxic risk of pain in their joint policy statement urging the avoidance, prevention, and possible elimination of pain even during routine minor procedures to protect the developing brain (55). Therefore, the safest course of action is avoidance of nonmedical and non-urgent surgeries, as recommended by the FDA
Science Board, as well as avoidance of iatrogenic procedural pain, as recommended by AAP-CPS, to protect the developing brain in infants. While pediatric surgeries are typically rare and cannot account for the high rates of SIDS, particularly if the cause of death is ascribed to the surgery, we suspect that a specific type of voluntary painful surgery concealed under the cloak of routine hospital practices account for the high volume of SIDS rates.

\section{Neonatal Circumcision}

Circumcision is one of the most common elective surgical procedures in the world and is performed primarily on males (56). Female circumcision is practiced in nearly 30 African countries, some Southeast Asian and Middle Eastern countries, and in immigrant communities in Europe and North America (57). Despite its relevancy, female neonatal circumcision will not be discussed here since in most western countries it is illegal and thereby under-reported and we lack SIDS data for the remaining countries. In North America, 1.2 million male infants are circumcised every year (58) often within the first 2 days of life (59). Although not requiring general anesthesia, circumcision is an intensively painful procedure requiring adequate analgesia (60). Circumcision is associated with intraoperative and postoperative risks, including bleeding, shock, sepsis, circulatory shock, and hemorrhage (61-63) that can result in death $(63,64)$.

Infant deaths following religious neonatal circumcision have been known for at least two millennia (65). Talmud (the central text of Rabbinic Judaism) sages ruled in the first centuries A.D. that mothers with two children who have died following the surgery should receive an exemption from circumcising their infants. During the nineteenth century, developments in medical knowledge on one hand and the rise of Jewish "Enlightenment" on the other hand, brought many Jews to reject the authority of the Talmud and with that the practice of circumcision. A new wave of accusations toward Jewish circumcisers (mohels) and rabbis of infant deaths following circumcision soon appeared and prompted community leaders to appeal to the governing authorities to forbid this practice - efforts that were countered by rabbis' threats to ban the admission of uncircumcised Jewish children from Jewish schools. The fierce arguments about the necessity of the procedure last to this day and led many Jews to opt their infants out of the procedure, including Theodor Herzl, one of the fathers of modern political Zionism (66). In the UK, Gairdner (67) estimated an annual rate of 16 per 100,000 circumcision-associated deaths for boys under 1-year old in a study that influenced the British government to exclude circumcision coverage from the National Health Service. Remarkably, the SIDS rates in the UK (0.38 per 1000) are much lower than in the USA (0.55 per 1000) (10) where most male infants are circumcised (58). Moreover, most of the deaths in the USA occur in non-Hispanic blacks (83\% higher death rate compared with non-Hispanic whites). SIDS rates were $44 \%$ lower for Hispanics compared with non-Hispanic whites (68). Interestingly the circumcision rates among Hispanics are about half that of the two other groups (69).

Circumcision contributes to the rise in allostatic load and increased risk for SIDS through multiple conduits. Circumcision produces crush and incisional injuries during amputation, 
resulting in damage to normal prepuce tissue, the associated nerves, and blood vessels. Wound healing manifested by hyperaemia and swelling at day 7 postoperative is observed in $70 \%$ of infants with minimally retractile prepuces seen in infants circumcised before 1 year of age with subsequent bacterial carriage of skin commensals (70). Circumcised males have increased pain responses to childhood immunization 4-6 months post-surgery $(71,72)$ consistent with central sensitization (73). The abnormal development of sensory pathways in the developing nervous system elicited by the pain during critical postnatal periods is manifested in later life following nociceptive reexposure by abnormal sensory thresholds and pain responses that are not restricted to the original site of postnatal trauma (74-76). Neonatal nociceptive exposure induces long-term hypoalgesia or hyperalgesia depending on the nature and timing of the trauma $(54,77)$ and is consistent with surgery and pain adversely impacting neurodevelopment independent of anesthetic (76).

Post-circumcision, tactile hypersensitivity increases due to post-surgical and -traumatic mechanisms that contribute toward allostasis and the risk of SIDS. This is evident by the increase in toll-like receptor 4 (78) associated with post-circumcision wound healing, which is also observed in post-surgical tactile hypersensitivity in males and dependent on testosterone (79). Following peripheral nerve injury, the purinergic receptors in the spinal cord microglial cells release BDNF (79) and mitogen-activated protein kinase p38 (80) that contribute to neuropathic pain and tactile hypersensitivity. Due to their testosterone dependency, they are seen only in males (79). The testosterone surge occurring during the first 2- to 4-month period may increase susceptibility to the initial stages of infection and is consistent with the peak in SIDS mortality (81).

Male neonates subjected to circumcision can experience severe cardiorespiratory pain responses, including cyanosis, apnea, increased heart rate (82), and increased pitch (fundamental frequency) of cry (as high as $800-2000 \mathrm{~Hz}$ ) associated with decreased heart rate variability, i.e., decreased vagotonia (83-85), a likely risk factor for SIDS. Other circumcision sequelae of sufficient severity to require emergency room evaluation or hospital admission and contribute toward allostasis include infection, urinary retention, inflammatory redness and swelling ascribed to healing $(86,87)$, and amputation/necrosis of the glans (88). Behavioral abnormalities, such as eating disturbance and disturbed sleep, are also the consequence of pain exposure (89).

Postoperative circumcision pain of ample severity to require analgesia is expected for about 10 days for healing with incomplete wound healing past day 14 seen in up to $6 \%$ of infants depends on the device used to amputate the foreskin (88), which is also associated with various adverse events $(56,90)$. The overall complication rate for circumcision ranges from 0.2 to $10 \%$ with many USA physicians performing the procedure without formal training, being unaware of contraindications, and incapable of handling post-op complications (56, 91, 92). Lower complication rates for early and late adverse events have been attributed to underreporting with late adverse events mistakenly not attributed to circumcision $(92,93)$. Consequently, the low number ascribed to circumcision as the cause of death
(63) may be underreported and erroneously attributed to other causes, such as sepsis (94) or SIDS.

One mechanism by which circumcision may elicit SIDS concerns the inhibition of nerves involved in nociception processing that produces prolonged apnea while impairing cortical arousal. Neonatal surgery that traumatizes peripheral nerves with associated tactile hypersensitivity followed by a subsequent surgery later in development can increase spinal cord microglia signaling and elicit persistent hyperalgesia (80). It can also produce post-surgical hyperalgesia that subsequently alters postnatal development of the rostral rostroventral medulla (RVM), which controls the excitability of spinal neurons by spinally projecting neurons from the nucleus paragigantocellularis lateralis (PGCL) and the nucleus raphe magnus. Alterations in the RVM result in a descending inhibition of spinal reflex excitability on nociception (95). Inhibition of RVM neurons was shown to limit the duration of the laryngeal chemoreflex and produce prolonged apnea that contributes toward SIDS, particularly when combined with stimuli that inhibit respiration (96). In SIDS, norepinephrine, which depresses respiration, is increased in the PGCL and serotonin $5-\mathrm{HT}_{1 \mathrm{~A}}$ receptor that mediates nociceptive stimuli in the brainstem (97) and decreased in the raphe nuclei and the arcuate nuclei (98). The reduction in $5-\mathrm{HT}_{1 \mathrm{~A}}$ receptors observed in the brainstem of SIDS infants prompts the hypothesis that SIDS is caused by a brainstem abnormality that impairs the ability to generate protective responses to lifethreatening challenges $(99,100)$. This hypothesis, however, does not explain why SIDS peaks at 2-4 months, rather than in an earlier GA (101). Orexin is another important regulator of both pain and sleep dysfunction. Orexin knockout mice presented greater degree of hyperalgesia induced by peripheral inflammation and less stress-induced analgesia than wild-type mice (102). In the rostral ventrolateral medulla and PGCL, orexin receptors are expressed in sympathoexcitatory bulbospinal neurons (103). A significantly decreased orexin immunoreactivity in the hypothalamus and pontine nuclei was observed in SIDS infants (104).

Another mechanism that can explain the SIDS toll following circumcision is the loss of $\sim 1-2$ ounces (oz) of blood out of a total of $\sim 11 \mathrm{oz}$ that a 3,000 gram male newborn has (105), the equivalent of $\sim 1-2$ blood donations in an adult. Excessive bleeding is highly common in circumcision with reports range from 0.1 to $35 \%(91,106)$ in neonates. However, even moderate bleeding puts the infant as risk, and, being an inherent part of the procedure, it is not reported as a complication. Blood loss of $2-2.5 \mathrm{oz}, \sim 15 \%$ of the total blood volume at birth, is sufficient to cause hypovolemia and death. Since a large fraction of newborns (26\%), particularly premature infants, weigh much less than 3,000 grams (107), a smaller amount of blood loss may trigger hypovolemic shock. Therefore, when bleeding an infant of low birth weight or GA, the effect may be pathological resulting in a reduced blood pressure that has been associated with obstructive sleep apnea (OSA), a condition where the walls of the throat relax and narrow during sleep, interrupting normal breathing (108). It is, therefore, not surprising that most of the deaths following circumcision in high-income countries were due to bleeding (63). While it is accepted that failure of neural 
mechanisms causing arousal from sleep may play a role in at least some SIDS cases [e.g., Ref. (109)], it is unclear what causes the initial failure of the respiratory control (110). Comparing the breathing characteristics of 40 infants who eventually died of SIDS with 607 healthy controls, Kato and colleagues reported that SIDS infants have a greater proportion of obstructive and mixed apneic episodes than the control group (111). Although the frequency of these episodes decreased with age, the decrease was smaller in the SIDS infants than in the controls, in support of either immature or impaired respiratory control. Looking at the data by gender, however, shows that only boys exhibit a difference in apnea frequency in support of an impaired respiratory control (11), perhaps due to circumcision.

To date, circumcision in the USA, despite being the most common pediatric surgery, has not been subjected to the same systematic scientific scrutiny looking at immediate and delayed adverse effects, including pain [e.g., Ref. (112)], nor has circumcision status been included as part of a thorough SIDS investigation/registry or analyses [e.g., Ref. (2)] in spite of the male predominance of both neonatal circumcision and SIDS. However, based on assessment of risk of harms versus benefit, despite the latter including decreased risk of urinary tract infection (113), the Royal Australasian College of Physicians, the British Medical Association, the Canadian Paediatric Society (87), and several west European medical societies have recommended against routine neonatal circumcision (114), arguing that the benefits of circumcision to children are minimal, non-existent, or outweighed by the risks, and that circumcision is thereby unwarranted. The AAP's recommendation in favor of this routine (115) has been widely criticized [e.g., Ref. (116)].

\section{Skin-Breaking Procedures}

Skin-breaking procedures are a large and diverse group of insults that contribute toward allostasis. Infants subjected to repetitive heel lances, the most common skin-breaking procedure in neonates, have increased pain responses to subsequent skin cleansing and venipuncture (117). Heel lances in newborns elicit nociceptive-specific EEG brain activity associated with reflex withdrawal dependent on the stimulus intensity in the absence of clinical pain, which is difficult to measure (118). Brain imaging of newborn infants demonstrates increased sensitivity to nociceptive stimuli with greater amplitude and duration of reflex withdrawal compared to adults (119). Goksan and colleagues (2015) reported the activation of 18 out of 20 brain areas (including anterior cingulate cortex, bilateral thalamus, all divisions of insular cortex, and primary somatosensory cortex) in infants in response to nociceptive stimuli. Seven-day-old newborns do not have activation of the amygdala, orbitofrontal cortex, or anterior division of the insular cortex, suggesting that reward value/anticipation of future outcomes/emotional significance may not be attached to the nociceptive stimuli at this early postnatal stage of development, although activation of anterior cingulate cortex may suggest perceived unpleasantness (119). Non-specific neuronal bursting activity in response to heel lances is seen on EEG in preterm infants ( $<35$ weeks of GA) while after 35-37 GA somatosensory potentials discriminate touch from nociceptive exposure (120). Exhibiting cortical activation following heel sticks is also associated with increase in heart rate and clinical pain behaviors (117), suggesting that preterm infants have at least the same increased pain response as neonates, with some studies suggesting a higher one (40).

The number of repetitive skin-breaking pain procedures (e.g., heel lance, intramuscular injection, tape removal, and intramuscular injection) in preterm infants (24-32 weeks) without neurodevelopmental, sensorimotor, or severe brain injury is significantly associated with decreased subcortical gray matter and maturation of white matter at term-equivalent age (40 weeks) (121). Overall, it is well established that intense and repetitive pain in early childhood is associated with negative life outcome (31) that contributes toward allostasis and thereby growing risk of SIDS.

\section{Inflammation, Birth Order, and Seasonality}

Waning of maternal antibody levels and/or low levels of acquired immunity followed by recent infection and inflammation during a developmental period in the infant may result in a dysregulated inflammatory response, a risk factor for SIDS (122, 123). Approximately one-half of SIDS victims have a slight upper airway infection before death (124) with males reported to have an excess of infant mortality from respiratory deaths as well as SIDS (125). The risk of SIDS also increases with the number of siblings, otherwise known as "birth order" (124), another known SIDS risk factor. Mage and Donner (23) proposed that the higher risk of SIDS with increasing birth order could be due to greater probability of exposure to respiratory viral infection via contact with a sibling. This assumption is reasonable, but it does not explain the excess in male mortality.

The association between respiratory illnesses and seasonality is also elusive. In some countries, the winter seasonal predominance of SIDS has declined or disappeared when the prevalence of infants sleeping in the prone position has decreased, in support of an interaction between sleeping position and factors more common during colder months (e.g., overheating and infection) (19). However, in other countries, SIDS was shown to have a small seasonality component, suggesting that seasonality is a risk factor (23), though it also does not explain why males are at higher risk.

We speculate that the winter seasonal predominance of SIDS is due to the increase in respiratory illnesses among household members that are in contact with the infant (126), particularly older siblings, that contributes toward the infant's allostatic load. Infants lose the protection of maternally acquired antibodies at 2-4 months of age (127), when they become susceptible to upper airway infections. At that time, even otherwise benign upper respiratory infections can augment the laryngeal cough reflex and produce prolonged apnea, an important risk factor for SIDS. This risk may be elevated among infants with an impaired immune system (128) and further elevated among circumcised infants struggling to regulate their allostatic exposures to the recent and new stressors (26) (Figure 1). 


\section{The Nightly SIDS Cascade}

Compared with other infants, those who subsequently succumb to SIDS have higher heart rates, reduced heart rate variations, abnormal QT intervals, increased baseline heart rates, and bradycardias preceding apnea or during ventilatory effort (129). In this section, we highlight some of the critical events in the nightly SIDS cascade.

Depending on the GA, nearly $90 \%$ of preterm infants experience intermittent hypoxia or recurrent apneas (130) attributable to central apnea, with obstructed breaths appearing during periods of prolonged central apnea (131). OSAs have been associated with postoperative pain $(132,133)$, increased norepinephrine and epinephrine levels (134), higher blood pressure (135), and upper airway hypotonia during rapid eye movement (REM) sleep due to decreased genioglossus activity (136). Repetitive apneas have also been associated with decreased arterial oxygen saturation and decreased cerebral oxygenation, which would have gone undiagnosed and thereby contribute toward the SIDS diagnosis (101). Such repetitive apneas may also contribute to higher cerebral oxidative stress, increased sympathetic activity, and hypoxic loss of neurons that alter or become less efficient in adulthood (137). These events are more frequent in the supine position and when the tonsils are swollen which accompany a number of upper respiratory tract infections. Unsurprisingly, infants succumbing to SIDS, who have been monitored, experienced significantly more frequent episodes of obstructive and mixed sleep apnea, especially males (111) during REM sleep (138). SIDS infants experience fewer cortical arousals during REM and non-REM (NREM) sleep, more subcortical activations in REM sleep of longer durations in both REM and NREM sleep, more frequent subcortical activations in the first part of night, and fewer cortical arousals in the early AM hours (138). Polygraphic changes, considered pathological, recorded in the brainstem of SIDS infants include apoptosis, hypoplasia, and gliosis (138).

Unusual breathing patterns and decreased heart rate variability may thereby indicate at-risk infants. Breathing patterns influence cardiovascular response $(131,139)$ with decreased heart rate variability in the neonate attributable in part to increased sympathetic activity and/or decreased parasympathetic activity with gradually increasing parasympathetic activity over the first year of life (140-142). Infants normally spend about $70 \%$ of a $24 \mathrm{~h}$ period asleep, and those who subsequently succumb to SIDS demonstrate a decreased heart rate variability due to increased sympathetic activity and/or decreased parasympathetic activity in all sleep phases (active/quiet sleep) $(129,140)$. Sympathetic activation/catecholamine release in response to hypoxia/hypercapnia is mediated by carotid body glomus cells acutely (143) and by peripheral chemoreceptor organs [e.g., adrenal medulla and oxygen sensing pulmonary neuroendocrine cells (PNEC)] (144). Lungs from infants dying of SIDS have demonstrated hyperplasia of PNEC with reduced myelination of its vagal afferents impairing oxygen sensing (145) as well as increased airway (146) and thick pulmonary arteries in males (147).

Channelopathies can induce cardiac arrhythmias, such as abnormal QT syndromes, catecholaminergic ventricular tachycardia, and prolonged QT interval associated with intracellular acidosis (148). We note that SIDS diagnosis may not be given to infants that suffer lethal arrhythmias or diagnosed with channelopathies, however channelopathies can inflict sudden unexpected death during infancy via a lethal ventricular arrhythmia without leaving a trace of structural evidence detectable during postmortem examination, in which case they are candidate suspects in the etiology of SIDS (149). Increasing QT interval is noted during early development up to four postnatal months followed by decreasing ECG's QT and PR intervals during childhood (150). Prolonged QT has been long associated with SIDS (151) and is a risk factor for ventricular arryhthmia with $50 \%$ of infants succumbing to SIDS observed to have prolonged QT interval during the first week of life (150). Hypoxia interferes with hemichannel function and maturation of the cardiac conduction system, which increases the risk of arrhythmogenic death (150). In this respect, mutations in genes associated with development of the cardiac conduction system (152) and cardiomyopathy (153) have been implied in SIDS, although the extent to which they contribute to SIDS remains under debate. While reports have estimated that up to $15 \%$ of SIDS were related to specific genetic variants [e.g., Ref. (154)], a recent study that sequenced the full exons of 64 genes associated with sudden death in the largest known cohort (351) of infant and young sudden death decedents reported that less than $4 \%$ of unexpected deaths were associated with a pathogenic genetic variant (155). These results suggest that many pathogenic variants involved in SIDS are unknown or, most likely, that pathogenic variants play a minute role is SIDS.

\section{The Significance of the Allostatic Load Model for SIDS}

Sudden infant death syndrome occurs when an infant dies suddenly, unexpectedly, and without a cause identified through a forensic autopsy or death-scene investigation. We speculate that SIDS is caused by prolonged and repetitive iatrogenic stressful, painful, or traumatic experiences during critical development stages that constitute allostatic overload (156). Over the past years, allostatic load models were proposed to explain several leading medical conditions, including mental health disorders $(157,158)$, preterm birth (159), and chronic stress (160).

While the infant's first environment is typically romanticized as peaceful, painless, hygienic, safe, and harmless, in practicality it may be anything but that. Already in the uterus, the fetus may be exposed to maternal substance use (e.g., smoking and drug use) associated with SIDS $(19,161)$. During a prolonged hospitalization in the Neonatal Intensive Care Unit that follows a preterm birth, infants may be exposed to extended and repeated pain, which thier unstable and immature physiological systems are unable to offset and will potentially render them more vulnerable to the effects of repeated invasive procedures (38). Neonatal circumcision typically involves maternal separation, pain, bleeding, and shock and, like any operation, puts the infant at risks of hemorrhage and sepsis even when anesthetic is used (67). The long-term consequences of circumcision include, among else, greater pain response to routine immunizations within the few months past birth (72). During winter time, the infant is at risk of infection and illnesses that grows with the number of household members, particularly older children (126), which explains why 
an elevated immune response is one of the hallmarks of SIDS $(123,128)$. Other common stressors may include birth trauma, birth injury, traumatic injury, life-threatening event, inadequate nutrition, heel lances, prolonged institutionalization, skin breaks, and air pollution - all contribute to the build-up of toxic allostatic load.

Our model represents a major departure from previous models, such as the "three interrelated causal spheres of influence model" that requires two out of three factors to act simultaneously (subclinical tissue damage, deficiency in postnatal development of reflexes and responses, and environmental factors) (162), or the more popular "triple-risk model," which advocates that the combined effect of three factors (vulnerable infant, critical development period, and environmental stressors) causes SIDS (163). Our model posits that any infant may succumb to SIDS when the combined and cumulative effect of the environmental stressors has exceeded their tolerance level shaped by their unique genetic and environmental factors (Figure 1).

\section{TESTING THE HYPOTHESIS}

Our hypothesis makes several testable predictions.

\section{Neonatal Circumcision is a Risk Factor for SIDS}

Double-blinded case-control human studies aiming to test our hypothesis are unfeasible due to ethical consideration and the difficulties in matching cases and controls (19). Fortunately, the prepuce has been well conserved throughout mammalian evolution (164), which attests to its functional importance, and allows carrying out animal studies. Our hypothesis can be tested by circumcising the prepuce of mammalian animal models and measuring whether an excess of SIDS is observed among cases when compared with untreated controls. Curiously, none of the studies purporting the "benefits" of neonatal circumcision has ever been demonstrated using animal models, which are the only viable means to carry out double-blinded case-control studies assessing the short- and long-term health impacts of circumcision. In humans, we can expect higher SIDS rates in Anglophone countries that adopted male neonatal circumcision in the nineteenth century, compared to Iberio-American that traditionally have opposed circumcision (66). We can also expect a higher incidence of SIDS in USA states where Medicaid, the most common health insurance, covers circumcision, compares to states where this procedure is not covered by Medicaid after accounting for culture and socioeconomic status. The data for such study can be obtained from the CDC's SIDS registry (165). Finally, we can compare the circumcision status of SIDS victims versus healthy controls, obtained through autopsies and questionnaires, respectively. New genetic tools, such as Case-control matcher (http://www.elhaik-lab.group.shef.ac.uk/ElhaikLab/index.php), based on biogeographic ancestry tools [e.g., Ref. (166)], can be instrumental in optimizing case-control matches by identifying individuals that have similar population structure and genetic background and minimizing the bias studies due to population stratification.

\section{Male Neonatal Circumcision Accounts for a Large Fraction of the Gender Bias in SIDS}

We speculate that the male bias in SIDS observed in western countries may be due to both natural protections that render females more resilient to nociceptive stimuli and legal-cultural ones that protect females from circumcision in these countries. The weights of these two factors are unknown, yet we expect the gender deviations from even proportions in SIDS to be correlated with circumcision rates. Consequently, large male bias is expected in societies that practice neonatal circumcision whereas smaller bias is expected in societies that circumcise both males and females or avoid it altogether.

\section{Circumcised Premature Infants Are at High Risk}

We predict that circumcised premature infants would be at higher risk for SIDS compared with intact preterm infants. This can be tested by an analysis of hospital records after properly matching cases with controls (19).

Additional complications that should be considered when testing these predictions in humans include misclassification of SIDS to other categories, inconsistent reports of SIDS over time in certain countries due to changes in definitions, inconsistent reports of circumcision (167), and the absence of legislation requiring an autopsy or thorough death-scene investigation.

\section{IMPLICATIONS OF THE HYPOTHESIS}

Our hypothesis denotes that while some infants are genetically more vulnerable to the effects of allostatic load, all infants living in a stress fraught environment may be at risk of SIDS. If proven, this hypothesis will generate a paradigm shift in our understanding of neonates and pain toward focusing on factors that contribute toward allostasis.

The implication of our hypothesis, which explains many of the findings already reported in the literature, is that environmental risks should be mapped and eliminated or mitigated to reduce cases of infant deaths. Many of these implications can be put to use immediately, such as applying pain management techniques to infants that experience repetitive pain, eliminating neonatal circumcisions when possible, and postponing non-medical circumcisions to later ages. We note that postponing the circumcision does not alleviate individuals from associated complications. Studies of female circumcision among adolescents consistently report major physical, psychological, and sociological complications following the surgery $(168,169)$.

Although at the time being identifying infants at higher risk for SIDS is impossible, our hypothesis predicts that they would be highly sensitive to pain which can be estimated, for example, from the pitch and tone of their cry following negative stimulus (170). Such approach requires developing a standardized method that yields a small percentage of false positives. Progress should also be made in screening for genetic variants that increase the risk for SIDS. 
In summary, SIDS is a complex, multifactorial syndrome in which continued research is needed to fully understand the relevant interactions between genetic and environmental risk factors that affect causation. We introduced an allostatic load model to explain SIDS and argued that it explains the main characteristic of this syndrome (Table 1). We also proposed how to test the hypothesis and offered guidelines on how to reduce the risk of SIDS.

\section{REFERENCES}

1. Mitchell EA, Krous HF. Sudden unexpected death in infancy: a historical perspective. J Paediatr Child Health (2015) 51:108-12. doi:10.1111/jpc.12818

2. Camperlengo L, Shapiro-Mendoza CK, Gibbs F. Improving sudden unexplained infant death investigation practices: an evaluation of the Centers for Disease Control and Prevention's SUID Investigation Training Academies. Am J Forensic Med Pathol (2014) 35:278-82. doi:10.1097/PAF.0000000000000123

3. Garstang J, Ellis C, Sidebotham P. An evidence-based guide to the investigation of sudden unexpected death in infancy. Forensic Sci Med Pathol (2015) 11:345-57. doi:10.1007/s12024-015-9680-x

4. NCBI PubMed. Available from: http://www.ncbi.nlm.nih.gov/ pubmed/?term $=$ Sudden+Infant+Death+Syndrome

5. Opdal SH, Rognum TO. The sudden infant death syndrome gene: does it exist? Pediatrics (2004) 114:e506-12. doi:10.1542/peds.2004-0683

6. Horne RS, Hauck FR, Moon RY. Sudden infant death syndrome and advice for safe sleeping. Br Med J (2015) 350:h1989. doi:10.1136/bmj.h1989

7. Hauck FR, Tanabe KO. International trends in sudden infant death syndrome: stabilization of rates requires further action. Pediatrics (2008) 122:660-6. doi:10.1542/peds.2007-0135

8. Hakeem GF, Oddy L, Holcroft CA, Abenhaim HA. Incidence and determinants of sudden infant death syndrome: a population-based study on 37 million births. World J Pediatr (2015) 11:41-7. doi:10.1007/s12519-014-0530-9

9. Waters KA. SIDS symposium-a perspective for future research. Paediatr Respir Rev (2014) 15:285-6. doi:10.1016/j.prrv.2014.09.005

10. Hauck FR, Tanabe KO. International trends in sudden infant death syndrome and other sudden unexpected deaths in infancy: need for better diagnostic standardization. Curr Pediatr Rev (2010) 6:95-101. doi:10.2174/157339610791317241

11. Hunt CE, Darnall RA, McEntire BL, Hyma BA. Assigning cause for sudden unexpected infant death. Forensic Sci Med Pathol (2015) 11:283-8. doi:10.1007/s12024-014-9650-8

12. Sauber-Schatz EK, Sappenfield WM, Shapiro-Mendoza CK. Comprehensive review of sleep-related sudden unexpected infant deaths and their investigations: Florida 2008. Matern Child Health J (2015) 19:381-90. doi:10.1007/ s10995-014-1520-1

13. Hauck FR, Tanabe KO, McMurry T, Moon RY. Evaluation of bedtime basics for babies: a national crib distribution program to reduce the risk of sleep-related sudden infant deaths. J Community Health (2015) 40:457-63. doi:10.1007/s10900-014-9957-0

14. Byard $\mathrm{R}$, Beal $\mathrm{S}$. Has changing diagnostic preference been responsible for the recent fall in incidence of sudden infant death syndrome in South Australia? J Paediatr Child Health (1995) 31:197-9. doi:10.1111/j.1440-1754.1995. tb00785.x

15. Malloy MH, MacDorman M. Changes in the classification of sudden unexpected infant deaths: United States, 1992-2001. Pediatrics (2005) 115:1247-53. doi:10.1542/peds.2004-2188

16. Läer K, Dörk T, Vennemann M, Rothämel T, Klintschar M. Polymorphisms in genes of respiratory control and sudden infant death syndrome. Int $J$ Legal Med (2015) 129:977-84. doi:10.1007/s00414-015-1232-0

17. Poetsch M, Todt R, Vennemann M, Bajanowski T. That's not it, either-neither polymorphisms in PHOX2B nor in MIF are involved in sudden infant death syndrome (SIDS). Int J Legal Med (2015) 129:985-9. doi:10.1007/ s00414-015-1213-3

18. Jensen LL, Banner J, Byard RW. Does $\beta$-APP staining of the brain in infant bed-sharing deaths differentiate these cases from sudden infant death syndrome? J Forensic Leg Med (2014) 27:46-9. doi:10.1016/j.jflm.2014.07.006

\section{AUTHOR CONTRIBUTIONS}

EE developed the hypothesis and wrote the paper.

\section{FUNDING}

EE was partially supported by MRC Confidence in Concept Scheme award 2014-University of Sheffield (Ref: MC_PC_14115).

19. Hunt CE, Hauck FR. Sudden infant death syndrome. Can Med Assoc J (2006) 174:1861-9. doi:10.1503/cmaj.051671

20. Phillips DP, Brewer KM, Wadensweiler P. Alcohol as a risk factor for sudden infant death syndrome (SIDS). Addiction (2011) 106:516-25. doi:10.1111/j.1360-0443.2010.03199.x

21. Trachtenberg FL, Haas EA, Kinney HC, Stanley C, Krous HF. Risk Factor Changes for Sudden Infant Death Syndrome After Initiation of Back-to-Sleep Campaign. Pediatrics (2012) 129:630-8. doi:10.1542/peds.2011-1419

22. Goldstein RD, Trachtenberg FL, Sens MA, Harty BJ, Kinney HC. Overall postneonatal mortality and rates of SIDS. Pediatrics (2016) 137:1-10. doi:10.1542/peds.2015-2298

23. Mage DT, Donner M. A unifying theory for SIDS. Int J Pediatr (2009) 2009:368270. doi:10.1155/2009/368270

24. Sterling P. Allostasis: a model of predictive regulation. Physiol Behav (2012) 106:5-15. doi:10.1016/j.physbeh.2011.06.004

25. Fagiolini M, Jensen CL, Champagne FA. Epigenetic influences on brain development and plasticity. Curr Opin Neurobiol (2009) 19:207-12. doi:10.1016/ j.conb.2009.05.009

26. McEwen BS, Gianaros PJ. Stress-and allostasis-induced brain plasticity. Annu Rev Med (2011) 62:431-45. doi:10.1146/annurev-med-052209-100430

27. McEwen BS, Gray JD, Nasca C. 60 years of neuroendocrinology: redefining neuroendocrinology: stress, sex and cognitive and emotional regulation. J Endocrinol (2015) 226:T67-83. doi:10.1530/JOE-15-0121

28. McEwen BS. Allostasis and allostatic load: implications for neuropsychopharmacology. Neuropsychopharmacology (2000) 22:108-24. doi:10.1016/ S0893-133X(99)00129-3

29. McEwen BS, Seeman T. Protective and damaging effects of mediators of stress. Elaborating and testing the concepts of allostasis and allostatic load. Ann N Y Acad Sci (1999) 896:30-47. doi:10.1111/j.1749-6632.1999.tb08103.x

30. Katz DA, Sprang G, Cooke C. Allostatic load and child maltreatment in infancy. Clin Case Stud (2011) 10:159-72. doi:10.1177/1534650111399121

31. Walker SM. Neonatal pain. Paediatr Anaesth (2014) 24:39-48. doi:10.1111/ pan. 12293

32. Tye K, Pollard I, Karlsson L, Scheibner V, Tye G. Caffeine exposure in utero increases the incidence of apnea in adult rats. Reprod Toxicol (1993) 7:449-52. doi:10.1016/0890-6238(93)90089-P

33. Mueller BR, Bale TL. Sex-specific programming of offspring emotionality after stress early in pregnancy. J Neurosci (2008) 28:9055-65. doi:10.1523/ JNEUROSCI.1424-08.2008

34. Page GG, Hayat MJ, Kozachik SL. Sex differences in pain responses at maturity following neonatal repeated minor pain exposure in rats. Biol Res Nurs (2011) 15:96-104. doi:10.1177/1099800411419493

35. Kudielka BM, Kirschbaum C. Sex differences in HPA axis responses to stress: a review. Biol Psychol (2005) 69:113-32. doi:10.1016/j.biopsycho.2004.11.009

36. Paterson DS, Trachtenberg FL, Thompson EG, Belliveau RA, Beggs AH, Darnall R, et al. Multiple serotonergic brainstem abnormalities in sudden infant death syndrome. JAMA (2006) 296:2124-32. doi:10.1001/ jama.296.17.2124

37. Malloy M. Prematurity and sudden infant death syndrome: United States 2005-2007. J Perinatol (2013) 33:470-5. doi:10.1038/jp.2012.158

38. Grunau RE, Holsti L, Peters JW. Long-term consequences of pain in human neonates. Semin Fetal Neonatal Med (2006) 11:268-75. doi:10.1016/ j.siny.2006.02.007

39. Grunau RE, Whitfield MF, Petrie-Thomas J, Synnes AR, Cepeda IL, Keidar A, et al. Neonatal pain, parenting stress and interaction, in relation to cognitive and motor development at 8 and 18 months in preterm infants. Pain (2009) 143:138-46. doi:10.1016/j.pain.2009.02.014 
40. Slater R, Fabrizi L, Worley A, Meek J, Boyd S, Fitzgerald M. Premature infants display increased noxious-evoked neuronal activity in the brain compared to healthy age-matched term-born infants. Neuroimage (2010) 52:583-9. doi:10.1016/j.neuroimage.2010.04.253

41. Anand K, Scalzo FM. Can adverse neonatal experiences alter brain development and subsequent behavior? Neonatology (2000) 77:69-82. doi:10.1159/000014197

42. Marcus DA. A review of perinatal acute pain: treating perinatal pain to reduce adult chronic pain. J Headache Pain (2006) 7:3-8. doi:10.1007/ s10194-006-0267-5

43. Cohen G, Katz-Salamon M, Malcolm G. A key circulatory defence against asphyxia in infancy - the heart of the matter! J Physiol (2012) 590:6157-65. doi:10.1113/jphysiol.2012.239145

44. Fyfe KL, Yiallourou SR, Wong FY, Odoi A, Walker AM, Horne RS. Gestational age at birth affects maturation of baroreflex control. J Pediatr (2015) 166:559-65. doi:10.1016/j.jpeds.2014.11.026

45. Fyfe KL, Yiallourou SR, Wong FY, Odoi A, Walker AM, Horne RS. The effect of gestational age at birth on post-term maturation of heart rate variability. Sleep (2015) 38:1635-44. doi:10.5665/sleep.5064

46. Fyfe KL, Odoi A, Yiallourou SR, Wong FY, Walker AM, Horne RS. Preterm infants exhibit greater variability in cerebrovascular control than term infants. Sleep (2015) 38:1411-21. doi:10.5665/sleep.4980

47. Hays SR, Deshpande JK. Newly postulated neurodevelopmental risks of pediatric anesthesia: theories that could rock our world. J Urol (2013) 189:1222-8. doi:10.1016/j.juro.2012.11.090

48. Rappaport BA, Suresh S, Hertz S, Evers AS, Orser BA. Anesthetic neurotoxicity - clinical implications of animal models. N Engl J Med (2015) 372:796-7. doi:10.1056/NEJMp1414786

49. Psaty BM, Platt R, Altman RB. Neurotoxicity of generic anesthesia agents in infants and children: an orphan research question in search of a sponsor. JAMA (2015) 313:1515-6. doi:10.1001/jama.2015.1149

50. Nasr VG, Davis JM. Anesthetic use in newborn infants: the urgent need for rigorous evaluation. Pediatr Res (2015) 78:2-6. doi:10.1038/pr.2015.58

51. Warner DO, Flick RP. Anaesthetics, infants, and neurodevelopment: case closed? The Lancet (2015) 387:239-50. doi:10.1016/S0140-6736(15)00669-8

52. Morriss FH Jr, Saha S, Bell EF, Colaizy TT, Stoll BJ, Hintz SR, et al. Surgery and neurodevelopmental outcome of very low birth weight infants. JAMA pediatrics (2014) 168:746-54. doi:10.1001/jamapediatrics.2014.307

53. Walker SM. Biological and neurodevelopmental implications of neonatal pain. Clin Perinatol (2013) 40:471-91. doi:10.1016/j.clp.2013.05.002

54. Li J, Kritzer E, Craig PE, Baccei ML. Aberrant synaptic integration in adult lamina I projection neurons following neonatal tissue damage. J Neurosci (2015) 35:2438-51. doi:10.1523/JNEUROSCI.3585-14.2015

55. American Academy of Pediatrics and Canadian Paediatric Society. Prevention and management of pain in the neonate: an update. Pediatrics (2006) 118:2231-41. doi:10.1542/peds.2006-2277

56. DeMaria J, Abdulla A, Pemberton J, Raees A, Braga LH. Are physicians performing neonatal circumcisions well-trained? Can Urol Assoc J (2013) 7:260-4. doi:10.5489/cuaj.200

57. UNICEF. Female Genital Mutilation/Cutting: A Statistical Overview and Exploration of the Dynamics of Change. UNICEF (2013). Available from: http://www.data.unicef.org/corecode/uploads/document6/uploaded_pdfs/ corecode/FGMC_Lo_res_Final_26.pdf

58. Weiss AJ, Elixhauser A. Trends in Operating Room Procedures in U.S. Hospitals, 2001-2011. Healthcare Cost and Utilization Project (HCUP) (2014). Available from: http://www.hcup-us.ahrq.gov/

59. American Pregnancy Association. Circumcision: Benefits, Procedures and Risks. (2015). Available from: http://americanpregnancy.org/labor-and-birth/ circumcision/

60. Ward RM, Stiers J, Buchi K. Neonatal medications. Pediatr Clin North Am (2015) 62:525-44. doi:10.1016/j.pcl.2014.11.012

61. Weiss HA, Larke N, Halperin D, Schenker I. Complications of circumcision in male neonates, infants and children: a systematic review. BMC Urol (2010) 10:2. doi:10.1186/1471-2490-10-2

62. Boyle GJ. Circumcision of infants and children: short-term trauma and long-term psychosexual harm. Adv Sex Med (2015) 5:22-38. doi:10.4236/ asm.2015.52004

63. Edler G, Axelsson I, Barker GM, Lie S, Naumburg E. Serious complications in male infant circumcisions in Scandinavia indicate that this always be performed as a hospital-based procedure. Acta Paediatr (2016) 105:842-50. doi:10.1111/apa.13402

64. Blackwell T. Ontario Newborn Bleeds to Death after Family Doctor Persuades Parents to Get Him Circumcised. (2015). Available from: http://news. nationalpost.com/health/ontario-newborn-bleeds-to-death-after-familydoctor-persuades-parents-to-get-him-circumcised

65. Leas BF, Umscheid CA. Neonatal herpes simplex virus type 1 infection and Jewish ritual circumcision with oral suction: a systematic review. J Pediatric Infect Dis Soc (2014) 4:126-31. doi:10.1093/jpids/piu075

66. Gollaher D. Circumcision: A History of the World's Most Controversial Surgery. New York: Basic Books (2001).

67. Gairdner D. The fate of the foreskin, a study of circumcision. Br Med J (1949) 2:1433-7. doi:10.1136/bmi.2.4642.1433

68. Mathews T, MacDorman MF. Infant mortality statistics from the 2009 period linked birth/infant death data set. Natl Vital Stat Rep (2013) 61:1-28.

69. Xu F, Markowitz LE, Sternberg MR, Aral SO. Prevalence of circumcision and herpes simplex virus type 2 infection in men in the United States: the National Health and Nutrition Examination Survey (NHANES), 1999-2004. Sex Transm Dis (2007) 34:479-84. doi:10.1097/01.olq.0000253335.41841.04

70. Tarhan H, Akarken I, Koca O, Ozgü I, Zorlu F. Effect of preputial type on bacterial colonization and wound healing in boys undergoing circumcision. Korean J Urol (2012) 53:431-4. doi:10.4111/kju.2012.53.6.431

71. Taddio A, Goldbach M, Ipp M, Stevens B, Koren G. Effect of neonatal circumcision on pain responses during vaccination in boys. The Lancet (1995) 345:291-2. doi:10.1016/S0140-6736(95)90278-3

72. Taddio A, Katz J, Ilersich AL, Koren G. Effect of neonatal circumcision on pain response during subsequent routine vaccination. The Lancet (1997) 349:599-603. doi:10.1016/S0140-6736(96)10316-0

73. Woolf CJ. Central sensitization: implications for the diagnosis and treatment of pain. Pain (2011) 152:S2-15. doi:10.1016/j.pain.2010.09.030

74. Beggs S. Long-term consequences of neonatal injury. Can J Psychiatry (2015) 60:176-80. doi:10.1177/070674371506000404

75. Noel M, Palermo TM, Chambers CT, Taddio A, Hermann C. Remembering the pain of childhood: applying a developmental perspective to the study of pain memories. Pain (2015) 156:31-4. doi:10.1016/j.pain.0000000000000001

76. Ririe DG. How long does incisional pain last: early life vulnerability could make it last a lifetime. Anesthesiology (2015) 122:1189-91. doi:10.1097/ ALN.0000000000000660

77. Schwaller F, Fitzgerald M. The consequences of pain in early life: injury-induced plasticity in developing pain pathways. Eur J Neurosci (2014) 39:344-52. doi:10.1111/ejn.12414

78. Chen L, Guo S, Ranzer MJ, DiPietro LA. Toll-like receptor 4 plays an essential role in early skin wound healing. J Invest Dermatol (2013) 133:258-67. doi:10.1038/jid.2012.267

79. Sorge RE, Mapplebeck JC, Rosen S, Beggs S, Taves S, Alexander JK, et al. Different immune cells mediate mechanical pain hypersensitivity in male and female mice. Nat Neurosci (2015) 18:1081-3. doi:10.1038/nn.4053

80. Schwaller F, Beggs S, Walker SM. Targeting p38 mitogen-activated protein kinase to reduce the impact of neonatal microglial priming on incision-induced hyperalgesia in the adult rat. Anesthesiology (2015) 122:1377-90. doi:10.1097/ALN.0000000000000659

81. Moscovis SM, Hall ST, Burns CJ, Scott RJ, Blackwell CC. The male excess in sudden infant deaths. Innate Immun (2014) 20:24-9. doi:10.1177/1753425913481071

82. O'Conner-Von S, Turner HN. American Society for Pain Management Nursing (ASPMN) position statement: male infant circumcision pain management. Pain Manag Nurs (2013) 14:379-82. doi:10.1016/j.pmn.2011.08.007

83. Porter FL, Miller RH, Marshall RE. Neonatal pain cries: effect of circumcision on acoustic features and perceived urgency. Child Dev (1986) 57:790-802. doi: $10.2307 / 1130355$

84. Porter FL, Porges SW, Marshall RE. Newborn pain cries and vagal tone: parallel changes in response to circumcision. Child Dev (1988) 59:495-505. doi:10.2307/1130327

85. Stewart AM, Lewis GF, Heilman KJ, Davila MI, Coleman DD, Aylward SA, et al. The covariation of acoustic features of infant cries and autonomic state. Physiol Behav (2013) 120:203-10. doi:10.1016/j.physbeh.2013.07.003

86. Gold G, Young S, O’Brien M, Babl FE. Complications following circumcision: presentations to the emergency department. J Paediatr Child Health (2015) 51:1158-63. doi:10.1111/jpc.12960 
87. Sorokan ST, Finlay JC, Jefferies AL, Canadian Paediatric Society, Fetus and Newborn Committee, Infectious Diseases and Immunization Committee. Newborn male circumcision. Paediatr Child Health (2015) 20:311-5.

88. Mavhu W, Larke N, Hatzold K, Ncube G, Weiss HA, Mangenah C, et al. A randomized noninferiority trial of AccuCirc device versus Mogen clamp for early infant male circumcision in Zimbabwe. J Acquir Immune Defic Syndr (2015) 69:e156-63. doi:10.1097/QAI.0000000000000694

89. Mitchell A, Boss BJ. Adverse effects of pain on the nervous systems of newborns and young children: a review of the literature. J Neurosci Nurs (2002) 34:228-36. doi:10.1097/01376517-200210000-00002

90. Simpson E, Carstensen J, Murphy P. Neonatal circumcision: new recommendations \& implications for practice. Mo Med (2014) 111:222-30.

91. Sinkey RG, Eschenbacher MA, Walsh PM, Doerger RG, Lambers DS, Sibai BM, et al. The GoMo study: a randomized clinical trial assessing neonatal pain with Gomco vs Mogen clamp circumcision. Am J Obstet Gynecol (2015) 212:664.e1-8. doi:10.1016/j.ajog.2015.03.029

92. Frisch M, Earp BD. Circumcision of male infants and children as a public health measure in developed countries: a critical assessment of recent evidence. Glob Public Health (2016) 19:1-16. doi:10.1080/17441692.2016.1184292

93. Ben Chaim J, Livne PM, Binyamini J, Hardak B, Ben-Meir D, Mor Y. Complications of circumcision in Israel: a one year multicenter survey. Isr Med Assoc J (2005) 7:368-70.

94. Gellis SS. Circumcision. Am J Dis Child (1978) 132:1168-9.

95. Walker SM, Fitzgerald M, Hathway GJ. Surgical injury in the neonatal rat alters the adult pattern of descending modulation from the rostroventral medulla. Anesthesiology (2015) 122:1391-400. doi:10.1097/ALN.0000000000000658

96. Van der Velde L, Curran AK, Filiano JJ, Darnall RA, Bartlett D Jr, Leiter JC. Prolongation of the laryngeal chemoreflex after inhibition of the rostral ventral medulla in piglets: a role in SIDS? J Appl Physiol (2003) 94:1883-95. doi:10.1152/japplphysiol.01103.2002

97. Massey CA, Kim G, Corcoran AE, Haynes RL, Paterson DS, Cummings KJ, et al. Development of brainstem 5-HT1a receptor-binding sites in serotonin-deficient mice. J Neurochem (2013) 126:749-57. doi:10.1111/jnc.12311

98. Machaalani R, Waters KA. Neurochemical abnormalities in the brainstem of the Sudden Infant Death Syndrome (SIDS). Paediatr Respir Rev (2014) 15:293-300. doi:10.1016/j.prrv.2014.09.008

99. Kinney HC, Richerson GB, Dymecki SM, Darnall RA, Nattie EE. The brainstem and serotonin in the sudden infant death syndrome. Annu Rev Pathol (2009) 4:517. doi:10.1146/annurev.pathol.4.110807.092322

100. Kinney HC, Thach BT. The sudden infant death syndrome. N Engl J Med (2009) 361:795-805. doi:10.1056/NEJMra0803836

101. Decima PF, Fyfe KL, Odoi A, Wong FY, Horne RS. The longitudinal effects of persistent periodic breathing on cerebral oxygenation in preterm infants. Sleep Med (2015) 16:729-35. doi:10.1016/j.sleep.2015.02.537

102. Watanabe S, Kuwaki T, Yanagisawa M, Fukuda Y, Shimoyama M. Persistent pain and stress activate pain-inhibitory orexin pathways. Neuroreport (2005) 16:5-8. doi:10.1097/00001756-200501190-00002

103. Shahid IZ, Rahman AA, Pilowsky PM. Orexin A in rat rostral ventrolateral medulla is pressor, sympatho-excitatory, increases barosensitivity and attenuates the somato-sympathetic reflex. Br J Pharmacol (2012) 165:2292-303. doi:10.1111/j.1476-5381.2011.01694.x

104. Hunt NJ, Waters KA, Rodriguez ML, Machaalani R. Decreased orexin (hypocretin) immunoreactivity in the hypothalamus and pontine nuclei in sudden infant death syndrome. Acta Neuropathol (2015) 130:185-98. doi:10.1007/ s00401-015-1437-9

105. Sisson TRC, Whalen LE, Telek A. The blood volume of infants. J Pediatr (1959) 55:430-46. doi:10.1016/S0022-3476(59)80084-6

106. Kaplan GW. Complications of circumcision. Urol Clin North Am (1983) 10:543-9.

107. Martin JA, Hamilton BE, Osterman MJ, Curtin SC, Matthews TJ. Births: final data for 2013. Natl Vital Stat Rep (2015) 64:1-65.

108. Walter LM, Yiallourou SR, Vlahandonis A, Sands SA, Johnson CA, Nixon GM, et al. Impaired blood pressure control in children with obstructive sleep apnea. Sleep Med (2013) 14:858-66. doi:10.1016/j.sleep.2013.01.015

109. Kahn A, Groswasser J, Franco P, Scaillet S, Sawaguchi T, Kelmanson I, et al. Sudden infant deaths: stress, arousal and SIDS. Early Hum Dev (2003) 75(Suppl):147-66. doi:10.1016/j.earlhumdev.2003.08.018

110. Thach BT. The role of respiratory control disorders in SIDS. Respir Physiol Neurobiol (2005) 149:343-53. doi:10.1016/j.resp.2005.06.011
111. Kato I, Groswasser J, Franco P, Scaillet S, Kelmanson I, Togari H, et al. Developmental characteristics of apnea in infants who succumb to sudden infant death syndrome. Am J Respir Crit Care Med (2001) 164:1464-9. doi:10.1164/ajrccm.164.8.2009001

112. Bisogni S, Dini C, Olivini N, Ciofi D, Giusti F, Caprilli S, et al. Perception of venipuncture pain in children suffering from chronic diseases. BMC Res Notes (2014) 7:735. doi:10.1186/1756-0500-7-735

113. Na AF, Tanny SP, Hutson JM. Circumcision: is it worth it for 21st-century Australian boys? J Paediatr Child Health (2015) 51:580-3. doi:10.1111/ jpc. 12825

114. Darby R. Risks, benefits, complications and harms: neglected factors in the current debate on non-therapeutic circumcision. Kennedy Inst Ethics J (2015) 25:1-34. doi:10.1353/ken.2015.0004

115. American Academy of Pediatrics Task Force on Circumcision. Circumcision policy statement. Pediatrics (2012) 130:585-6. doi:10.1542/peds.2012-1989

116. Frisch M, Aigrain Y, Barauskas V, Bjarnason R, Boddy SA, Czauderna P, et al. Cultural bias in the AAP's 2012 technical report and policy statement on male circumcision. Pediatrics (2013) 131:796-800. doi:10.1542/peds.2012-2896

117. Taddio A, Shah V, Gilbert-MacLeod C, Katz J. Conditioning and hyperalgesia in newborns exposed to repeated heel lances. JAMA (2002) 288:857-61. doi:10.1001/jama.288.7.857

118. Hartley C, Goksan S, Poorun R, Brotherhood K, Mellado GS, Moultrie F, et al. The relationship between nociceptive brain activity, spinal reflex withdrawal and behaviour in newborn infants. Sci Rep (2015) 5:1-13. doi:10.1038/ srep12519

119. Goksan S, Hartley C, Emery F, Cockrill N, Poorun R, Moultrie F, et al. fMRI reveals neural activity overlap between adult and infant pain. Elife (2015) 4:e06356. doi:10.7554/eLife.06356

120. Fabrizi L, Slater R, Worley A, Meek J, Boyd S, Olhede S, et al. A shift in sensory processing that enables the developing human brain to discriminate touch from pain. Curr Biol (2011) 21:1552-8. doi:10.1016/j.cub.2011.08.010

121. Brummelte S, Grunau RE, Chau V, Poskitt KJ, Brant R, Vinall J, et al. Procedural pain and brain development in premature newborns. Ann Neurol (2012) 71:385-96. doi:10.1002/ana.22267

122. Blackwell C, Moscovis S, Hall S, Burns C, Scott RJ. Exploring the risk factors for sudden infant deaths and their role in inflammatory responses to infection. Front Immunol (2015) 6:44. doi:10.3389/fimmu.2015.00044

123. Ferrante L, Opdal SH. Sudden infant death syndrome and the genetics of inflammation. Front Immunol (2015) 6:63. doi:10.3389/fimmu.2015. 00063

124. Arnestad M, Andersen M, Vege A, Rognum TO. Changes in the epidemiological pattern of sudden infant death syndrome in southeast Norway, 1984-1998: implications for future prevention and research. Arch Dis Child (2001) 85:108-15. doi:10.1136/adc.85.2.108

125. Mage DT, Donner EM. Is excess male infant mortality from sudden infant death syndrome and other respiratory diseases X-linked? Acta Paediatr (2013) 103:188-93. doi:10.1111/apa.12482

126. Guntheroth WG. Crib Death: The Sudden Infant Death Syndrome. 3rd ed. Armonk, New York: Futura Publishing Co (1995).

127. Waaijenborg S, Hahné SJ, Mollema L, Smits GP, Berbers GA, van der Klis FR, et al. Waning of maternal antibodies against measles, mumps, rubella, and varicella in communities with contrasting vaccination coverage. J Infect Dis (2013) 208:10-6. doi:10.1093/infdis/jit143

128. Ferrante L, Rognum TO, Vege Å, Nygård S, Opdal SH. Altered gene expression and possible immunodeficiency in cases of sudden infant death syndrome. Pediatr Res (2016) 80:77-84. doi:10.1038/pr.2016.45

129. Horne RS, Nixon GM. The role of physiological studies and apnoea monitoring in infants. Paediatr Respir Rev (2014) 15:312-8. doi:10.1016/ j.prrv.2014.09.007

130. Prabhakar NR, Peng YJ, Kumar GK, Nanduri J. Peripheral chemoreception and arterial pressure responses to intermittent hypoxia. Compr Physiol (2015) 5:561-77. doi:10.1002/cphy.c140039

131. Indic P, Paydarfar D, Barbieri R. Point process modeling of interbreath interval: a new approach for the assessment of instability of breathing in neonates. IEEE Trans Biomed Eng (2013) 60:2858-66. doi:10.1109/TBME.2013. 2264162

132. Chung SA, Yuan H, Chung F. A systemic review of obstructive sleep apnea and its implications for anesthesiologists. Anesth Analg (2008) 107:1543-63. doi:10.1213/ane.0b013e318187c83a 
133. Chouchou F, Khoury S, Chauny JM, Denis R, Lavigne GJ. Postoperative sleep disruptions: a potential catalyst of acute pain? Sleep Med Rev (2014) 18:273-82. doi:10.1016/j.smrv.2013.07.002

134. Hakim F, Gozal D, Kheirandish-Gozal L. Sympathetic and catecholaminergic alterations in sleep apnea with particular emphasis on children. Front Neurol (2012) 3:7. doi:10.3389/fneur.2012.00007

135. Kang KT, Chiu SN, Weng WC, Lee PL, Hsu WC. Analysis of 24-hour ambulatory blood pressure monitoring in children with obstructive sleep apnea: a hospital-based study. Medicine, Balt (2015) 94:e1568. doi:10.1097/ MD.0000000000001568

136. McSharry DG, Saboisky JP, Deyoung P, Jordan AS, Trinder J, Smales E, et al. Physiological mechanisms of upper airway hypotonia during REM sleep. Sleep (2014) 37:561-9. doi:10.5665/sleep.3498

137. Dalmases M, Torres M, Márquez-Kisinousky L, Almendros I, Planas AM, Embid C, et al. Brain tissue hypoxia and oxidative stress induced by obstructive apneas is different in young and aged rats. Sleep (2014) 37:1249-56. doi:10.5665/sleep. 3848

138. Kato I, Franco P, Groswasser J, Scaillet S, Kelmanson I, Togari H, et al. Incomplete arousal processes in infants who were victims of sudden death. Am J Respir Crit Care Med (2003) 168:1298-303. doi:10.1164/ rccm.200301-134OC

139. Longin E, Dimitriadis C, Shazi S, Gerstner T, Lenz T, König S. Autonomic nervous system function in infants and adolescents: impact of autonomic tests on heart rate variability. Pediatr Cardiol (2009) 30:311-24. doi:10.1007/ s00246-008-9327-8

140. Schechtman VL, Raetz SL, Harper RK, Garfinkel A, Wilson AJ, Southall DP, et al. Dynamic analysis of cardiac R-R intervals in normal infants and in infants who subsequently succumbed to the sudden infant death syndrome. Pediatr Res (1992) 31:606-12. doi:10.1203/00006450-199206000-00014

141. Schechtman VL, Henslee JA, Harper RM. Developmental patterns of heart rate and variability in infants with persistent apnea of infancy. Early Hum Dev (1998) 50:251-62. doi:10.1016/S0378-3732(97)00047-7

142. Eyre EL, Duncan MJ, Birch SL, Fisher JP. The influence of age and weight status on cardiac autonomic control in healthy children: a review. Auton Neurosci (2014) 186:8-21. doi:10.1016/j.autneu.2014.09.019

143. Fernández-Agüera $\mathrm{MC}$, Gao L, González-Rodríguez P, Pintado CO, Arias-Mayenco I, García-Flores P, et al. Oxygen sensing by arterial chemoreceptors depends on mitochondrial complex I signaling. Cell Metab (2015) 22:825-37. doi:10.1016/j.cmet.2015.09.004

144. Sunday ME. Oxygen, gastrin-releasing peptide, and pediatric lung disease: life in the balance. Front Pediatr (2014) 2:72. doi:10.3389/fped.2014.00072

145. Cutz E. Hyperplasia of pulmonary neuroendocrine cells in infancy and childhood. Semin Diagn Pathol (2015) 32:420-37. doi:10.1053/ j.semdp.2015.08.001

146. Elliot J, Vullermin P, Carroll N, James A, Robinson P. Increased airway smooth muscle in sudden infant death syndrome. Am J Respir Crit Care Med (1999) 160:313-6. doi:10.1164/ajrccm.160.1.9802024

147. Krous HF, Haas E, Hampton CF, Chadwick AE, Stanley C, Langston C. Pulmonary arterial medial smooth muscle thickness in sudden infant death syndrome: an analysis of subsets of 73 cases. Forensic Sci Med Pathol (2009) 5:261-8. doi:10.1007/s12024-009-9116-6

148. Wilders R. Cardiac ion channelopathies and the sudden infant death syndrome. ISRN Cardiol (2012) 2012:1-28. doi:10.5402/2012/846171

149. Tester DJ, Ackerman MJ. Sudden infant death syndrome: how significant are the cardiac channelopathies? Cardiovasc Res (2005) 67:388-96. doi:10.1016/ j.cardiores.2005.02.013

150. Neary MT, Breckenridge RA. Hypoxia at the heart of sudden infant death syndrome? Pediatr Res (2013) 74:375-9. doi:10.1038/pr.2013.122

151. Perticone F, Ceravolo R, Maio R, Cosco C, Mattioli PL. Heart rate variability and sudden infant death syndrome. Pacing Clin Electrophysiol (1990) 13:2096-9. doi:10.1111/j.1540-8159.1990.tb06949.x

152. Evans A, Bagnall RD, Duflou J, Semsarian C. Postmortem review and genetic analysis in sudden infant death syndrome: an 11-year review. Hum Pathol (2013) 44:1730-6. doi:10.1016/j.humpath.2013.01.024

153. Santori M, Blanco-Verea A, Gil R, Cortis J, Becker K, Schneider PM, et al. Broad-based molecular autopsy: a potential tool to investigate the involvement of subtle cardiac conditions in sudden unexpected death in infancy and early childhood. Arch Dis Child (2015) 100:952-6. doi:10.1136/ archdischild-2015-308200

154. Van Norstrand DW, Ackerman MJ. Sudden infant death syndrome: do ion channels play a role? Heart Rhythm (2009) 6:272-8. doi:10.1016/ j.hrthm.2008.07.028

155. Methner DN, Scherer SE, Welch K, Walkiewicz M, Eng CM, Belmont JW, et al. Postmortem genetic screening for the identification, verification, and reporting of genetic variants contributing to the sudden death of the young. Genome Res (2016) 26:1170-7. doi:10.1101/gr.195800.115

156. McEwen BS. Stress, adaptation, and disease. Allostasis and allostatic load. Ann N Y Acad Sci (1998) 840:33-44. doi:10.1111/j.1749-6632.1998.tb09546.x

157. Berger M, Juster RP, Sarnyai Z. Mental health consequences of stress and trauma: allostatic load markers for practice and policy with a focus on Indigenous health. Australas Psychiatry (2015) 23:644-9. doi:10.1177/1039856215608281

158. Elhaik E, Zandi P. Dysregulation of the NF- $\mathrm{kB}$ pathway as a potential inducer of bipolar disorder. J Psychiatr Res (2015) 70:18-27. doi:10.1016/ j.jpsychires.2015.08.009

159. Christiaens I, Hegadoren K, Olson DM. Adverse childhood experiences are associated with spontaneous preterm birth: a case-control study. BMC Med (2015) 13:124. doi:10.1186/s12916-015-0353-0

160. Juster RP, McEwen BS, Lupien SJ. Allostatic load biomarkers of chronic stress and impact on health and cognition. Neurosci Biobehav Rev (2010) 35:2-16. doi:10.1016/j.neubiorev.2009.10.002

161. Carpenter R, McGarvey C, Mitchell EA, Tappin DM, Vennemann MM, Smuk M, et al. Bed sharing when parents do not smoke: is there a risk of SIDS? An individual level analysis of five major case-control studies. BMJ Open (2013) 3:e002299. doi:10.1136/bmjopen-2012-002299

162. Emery J. A way of looking at the causes of crib death. In: Tildon J, Roeder L, Steinschneider A, editors. Proceedings of the International Research Conference on the Sudden Infant Death Syndrome. New York: Academic Press (1983). p. 123-32.

163. Filiano J, Kinney H. A perspective on neuropathologic findings in victims of the sudden infant death syndrome: the triple-risk model. Biol Neonate (1994) 65:194-7. doi:10.1159/000244052

164. Cold CJ, Taylor JR. The prepuce. Br JUrol (1999) 83:34-44. doi:10.1046/j.1464-410x.1999.0830s1034.x

165. Shapiro-Mendoza CK, Camperlengo LT, Kim SY, Covington T. The sudden unexpected infant death case registry: a method to improve surveillance. Pediatrics (2012) 129:e486-93. doi:10.1542/peds.2011-0854

166. Elhaik E, Tatarinova T, Chebotarev D, Piras IS, Maria Calò C, De Montis A, et al. Geographic population structure analysis of worldwide human populations infers their biogeographical origins. Nat Commun (2014) 5 . doi:10.1038/ncomms4513

167. Risser JM, Risser WL, Eissa MA, Cromwell PF, Barratt MS, Bortot A. Self-assessment of circumcision status by adolescents. Am J Epidemiol (2004) 159:1095-7. doi:10.1093/aje/kwh149

168. Mulongo P, Hollins Martin C, McAndrew S. The psychological impact of Female Genital Mutilation/Cutting (FGM/C) on girls/women's mental health: a narrative literature review. J Reprod Infant Psychol (2014) 32:1-17. doi:10.1080/02646838.2014.949641

169. Saraçoglu M, Öztürk H. Female circumcision. Androl Gynecol Curr Res (2014) 2:1-3. doi:10.4172/2327-4360.1000120

170. Warnock F, Sandrin D. Comprehensive description of newborn distress behavior in response to acute pain (newborn male circumcision). Pain (2004) 107:242-55. doi:10.1016/j.pain.2003.11.006

Conflict of Interest Statement: The author declares that the research was conducted in the absence of any commercial or financial relationships that could be construed as a potential conflict of interest.

Copyright (c) 2016 Elhaik. This is an open-access article distributed under the terms of the Creative Commons Attribution License (CC BY). The use, distribution or reproduction in other forums is permitted, provided the original author(s) or licensor are credited and that the original publication in this journal is cited, in accordance with accepted academic practice. No use, distribution or reproduction is permitted which does not comply with these terms. 